\title{
ESPACIALIZAÇÃO DA PROBABILIDADE DE OCORRÊNCIA DE ALAGAMENTOS (PROB) E DO NÚMERO ESPERADO DE ALAGAMENTOS (NEA) NO MUNICÍPIO DE CURITIBA - PR
}

\author{
Marciel Lohmann ${ }^{(\mathrm{a})}$, Leonardo José Cordeiro Santos ${ }^{(\mathrm{b})}$, Camila Cunico ${ }^{(\mathrm{c})}$, Ronaldo Ferreira \\ Maganhotto $^{(\mathrm{d})}$ \\ (a) Departamento de Geociências, Universidade Estadual de Londrina, marciel_lohmann @yahoo.com.br \\ (b) Departamento de Geografia, Universidade Federal do Paraná, santos.ufpr@ gmail.com \\ (c) Departamento de Geociências, Universidade Federal da Paraíba, camilacunico@yahoo.com.br \\ (d) Departamento de Turismo, Universidade Estadual do Centro Oeste, ronaldomaganhotto@gmail.com
}

\section{Eixo: GEOGRAFIA FÍSICA E DESASTRES NATURAIS}

\begin{abstract}
Resumo
O presente trabalho se propõe espacializar a probabilidade de ocorrência de alagamentos bem como o número esperado de alagamentos nas bacias que compõem o município de Curitiba - PR. Para alcançar o objetivo proposto, foram construídos modelos baseados em regressão do tipo logística e redes de Kohonen (Self Organizing Map (SOM)) para a previsão probabilística de alagamentos. Foram utilizados os dados de precipitação estimada a partir da integração das informações provenientes de radar meteorológico, satélite e pluviômetros, utilizando o método de Análise Objetiva Estatística (ANOBES). Como proposta final, sugere-se que os resultados gerados neste trabalho integrem um Sistema de Alertas de Alagamentos em Curitiba, e que as informações e dados gerados possam ser utilizados pela Defesa Civil no sentido de aumentar a resiliência da população e mitigar possíveis impactos decorrentes dos alagamentos.
\end{abstract}

Palavras chave: Alagamentos, Probabilidade, Rede Neural.

\section{Introdução}

As estatísticas sobre a incidência de desastres induzidos por fenômenos naturais extremos no mundo contemporâneo revelam a tendência para a preponderância de fenômenos de origem hidroclimática, como sejam inundações e tempestades (MUNICH-RE, 2005). Levando em consideração tal afirmação e pensando o modelo de urbanização adotado em grandes cidades mundiais nota-se que em muitos casos é permitido a ocupação das planícies de inundação dos cursos d'água urbanos o que expõe a população ao risco de impactos de inundações e alagamentos, agravados pelos episódios anômalos de precipitação. Em regiões tropicais e subtropicais, por exemplo, em que as precipitações são mais frequentes, as inundações e alagamentos decorrentes de chuvas intensas são fenômenos comuns e também conhecidos como eventos extremos. Tais eventos fazem parte da dinâmica climática de um local, e podem tornar-se desastres quando "superam a capacidade material de uma determinada organização social para absorver, amortizar ou evitar seus efeitos negativos" (GONÇALVES, 2003). 
No caso brasileiro, as características sociais e ambientais de diversas cidades, tais como os processos de impermeabilização do solo e parcela considerável da população ocupando fundos de vale e planícies de inundação, acarretaram problemas crônicos de inundações nos últimos anos, causando grandes impactos em áreas urbanas, prejudicando as condições de vida da população e provocando prejuízos econômicos.

Assim, uma das maiores dificuldades quanto à prevenção dos impactos pluviais reside no fato de que toda a estrutura urbana, quando "planejada", utiliza como parâmetro apenas os dados médios referentes aos fenômenos meteorológicos, desconsiderando as anomalias que fazem parte do clima local, e que esporadicamente ocorrem.

Portanto, a chuva é o principal elemento deflagrador dos desastres relacionados a inundações e alagamentos, mas a ocupação inadequada de áreas sujeitas a alagamentos é o principal componente da vulnerabilidade da população frente a esses eventos, e decorrem de processos políticos, econômicos e culturais.

Especificamente para bacias integradas em áreas urbanas, necessita-se cada vez mais, criar condições para o monitoramento dos eventos extremos principalmente, em alta resolução, gerando um ambiente refinado de avaliação, permitindo ser utilizado como base em diversas áreas do conhecimento. Assim, gera-se dados base para estudos, aprimora-se modelos que podem vir a nortear políticas públicas de médio e longo prazos de maneira mais eficaz e precisa.

De acordo com Perez Filho et al (2006), a iniciativa de implantação de bacias urbanas monitoradas e voltadas para o estudo de eventos extremos num contexto pluvio-fluvial, assim como suas aplicações na gestão e planejamento urbano são de extrema importância no Brasil, o que a coloca como fundamental para o balizamento de demais estudos que possam se adequar à realidade físico-natural (geomorfológica, climática, pedológica) e social (o padrão de ocupações das cidades brasileiras).

Levando em consideração tal problemática, constata-se que os problemas relacionados aos eventos extremos de caráter dinâmico e complexo também afetam a Região Metropolitana de Curitiba, onde está inserido o município de Curitiba, verificados principalmente em função dos efeitos do impulso do crescimento urbano ao longo das últimas décadas.

Com tal problemática, o objetivo deste trabalho foi, espacializar a probabilidade de ocorrência de algamentos bem como o número esperado de alagamentos nas bacias que compõem o município de Curitiba - PR (Figura 1).

Reconhece-se que tais informações devem possibilitar o aprimoramento das ações de proteção por parte da Defesa Civil no sentido de retirar pessoas de áreas de risco, subsidiar medidas em tempo real para 


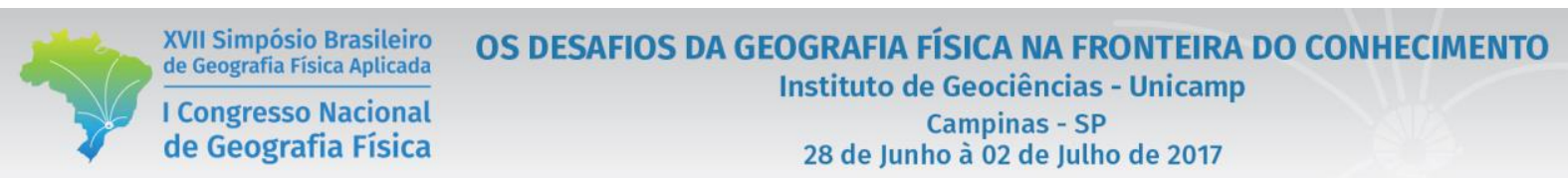

ordenação do trânsito, proteção de bens materiais e até mesmo para evitar a perda de vidas. Ainda, vem diretamente ao encontro das diretrizes gerais propostas nos planos diretores, no sentido da prevenção contra alagamentos e inundações no Município.

Vislumbra-se também como contribuição a utilização do conhecimento gerado para construção de um sistema de alerta a alagamentos em Curitiba baseado em estratégia probabilística para emissão de alertas, favorecendo o desenvolvimento das ações não só na eminência e no momento da ocorrência do alagamento, mas no pós-ocorrência e no planejamento futuro de médio e longo prazo. Nesse sentido, contribui também como medida não estrutural de controle dos alagamentos.

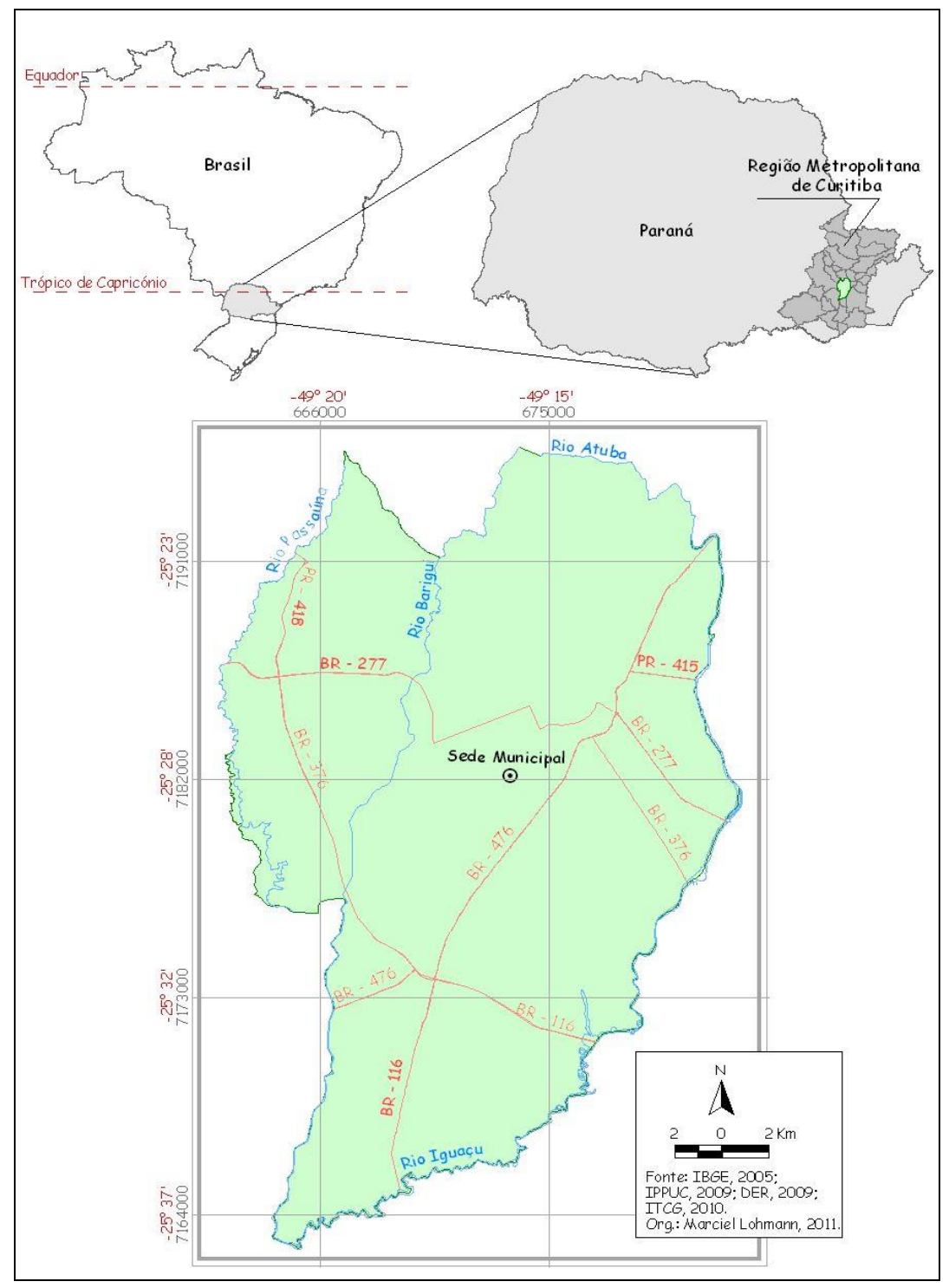

Figura 1 - Mapa de localição da área de estudo 


\section{Metodologia}

\subsection{Dados de alagamentos}

A coleta de dados referentes aos pontos/endereços afetados pelos alagamentos no município de Curitiba foi realizada junto ao Instituto de Pesquisa e Planejamento Urbano de Curitiba (IPPUC). Esses dados, no entanto possuem como fonte primária a Defesa Civil Municipal de Curitiba, já que a mesma, via contato telefônico ou atendimento "in loco" extrai as coordenadas (latitude e longitude) e espacializa tais dados, transformando-os em um arquivo tabular. Para este trabalho os dados utilizados foram do ano de 2005 até 2010, sendo os mesmos transformados em um arquivo vetorial do tipo ponto.

\subsection{Previsões de probabilidade}

Para caracterizar a ocorrência de alagamentos em Curitiba, optou-se por apresentar duas variáveis representativas para esta distribuição que são:

(1) Probabilidade de ocorrência de alagamentos (PROB);

(2) Número esperado de alagamentos (NEA).

A variável PROB pode ser representada por:

$$
P R O B=1-P[N A=\emptyset]
$$

Onde:

$\mathrm{NA}=$ Número de alagamentos

A variável NEA pode ser representada por :

$$
N E A=\sum_{i=0}^{N M A} \mathrm{P}[\mathrm{NA}=\mathrm{i}] \mathrm{i}
$$

Onde:

NMA: Número máximo de alagamentos

Com tal definição, a variável PROB e a variável NEA foram calculadas utilizando-se a rede neural do tipo SOM (Self Organizing Maps), que é formada por um conjunto de elementos simples, chamados neurônios, organizados em estruturas mais complexas, que funcionam em conjunto: a rede. Cada neurônio é uma unidade de processamento que recebe estímulos (de fora do sistema ou de outros neurônios), e produz uma resposta (para outros neurônios ou para fora do sistema).

Para a geração das previsões probabilísticas de alagamentos via a rede SOM, foi definido um conjunto de preditores, sendo constituídos pelas séries de chuva acumulada de 6 em 6 horas para 4 dias ou seja, chuva 


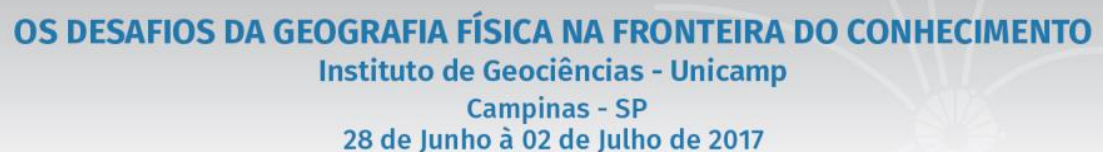

28 de Junho à 02 de Julho de 2017

ao longo de 96 h, a partir de sua decomposição em 16 valores recursivos de 6 horas (diferenças entre a chuva acumulada no tempo $t$ e $t$ - 6 ). Os dados de precipitação foram dados estimados a partir da integração das informações provenientes de radar meteorológico, satélite e pluviômetros, utilizando o método de Análise Objetiva Estatística (ANOBES)

Os procedimentos foram executados utilizando o pacote de treinamento SOM desenvolvido por Kohonen, tendo como base o sistema operacional Linux bem como todas as funções para inicialização do SOM, treino e mensuração do erro, chamado de erro de quantização.

A espacialização do NEA, assim como para a probabilidade poderia ser feita associando o NEA aos limites da bacia ou então a Curitiba como um todo, no entanto sem uma unidade métrica definida em termos de alagamentos por área. Dessa forma, optou-se por espacializar o NEA por $\mathrm{km}^{2}$ de área, já que tal unidade é de fácil compreensão. Tal espacialização gerou ainda uma informação secundária que trata-se da identificação dos locais com maior probabilidade de ocorrência de novos alagamentos.

Sendo assim teve-se como premissa de que a partir da análise histórica dos locais em que já ocorreu um alagamento no passado, há também maior probabilidade de ocorrer novos alagamentos. Portanto, a ideia básica foi caracterizar os possíveis locais de ocorrência a partir do histórico ocorrido. Para tanto, inicialmente foram compilados em um arquivo todos os pontos referentes aos alagamentos do período analisado. Tal procedimento foi elaborado com a ferramenta "merge" presente no ArcGIS 10.

Em uma etapa posterior, foi criado um arquivo formato "shape" (.shp) com uma grade regular de $1 \mathrm{x} 1 \mathrm{~km}$, utilizando como base o limite de Curitiba. Associado a grade necessitava-se definir uma área de abrangência para cada ponto registrado como alagamento. Sabe-se que um alagamento não é pontual e sim possui uma área de abrangência. No entanto, a informação disponível estava em formato pontual. Em função da inexistência de tal informação e sem indicação na literatura específica sobre a área média atingida para um alagamento em Curitiba, partiu-se para a busca desta informação com técnicos da Defesa Civil e Bombeiros, indicando que poderia ser estabelecido como área de abrangência um círculo de raio em torno de 250 e $300 \mathrm{~m}$. Sendo assim, optou-se por utilizar um raio de $300 \mathrm{~m}$ para cada alagamento ocorrido.

A partir de tal definição foi criado um arquivo de "buffer" (raio ao redor de um ponto) de 300m no entorno de todas as ocorrências de alagamentos mapeadas de 2005 a 2010, ou seja, todo o histórico correspondente ao período analisado. De posse destes dois arquivos procedeu-se para a realização de uma interseção (intersect), objetivando encontrar qual a área de cada buffer estava contida em cada pixel da grade de 1 x $1 \mathrm{~km}$. Com o arquivo gerado, foi realizada a junção espacial (spatial join) que permite estabelecer o relacionamento espacial entre dois temas, ou seja, é feita a junção de dados da tabela de 


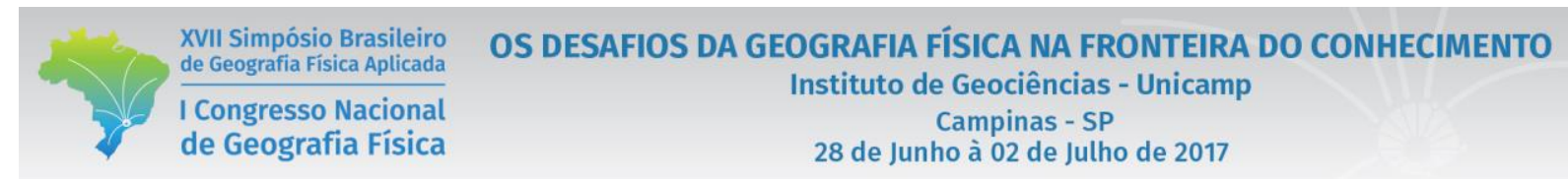

atributos de um tema à tabela de atributos de outro tema. $\mathrm{O}$ arquivo de grade recebeu os dados da tabela do arquivo de buffer. Utilizando-se da ferramenta "join”, pode-se finalmente juntar o valor do somatório das áreas dos buffers a tabela de atributos do arquivo de grade.

A Figura 2 ilustra a grade, os buffers e o resultado da operação "Spatial Join”, que gerou um arquivo de grade vetorial.

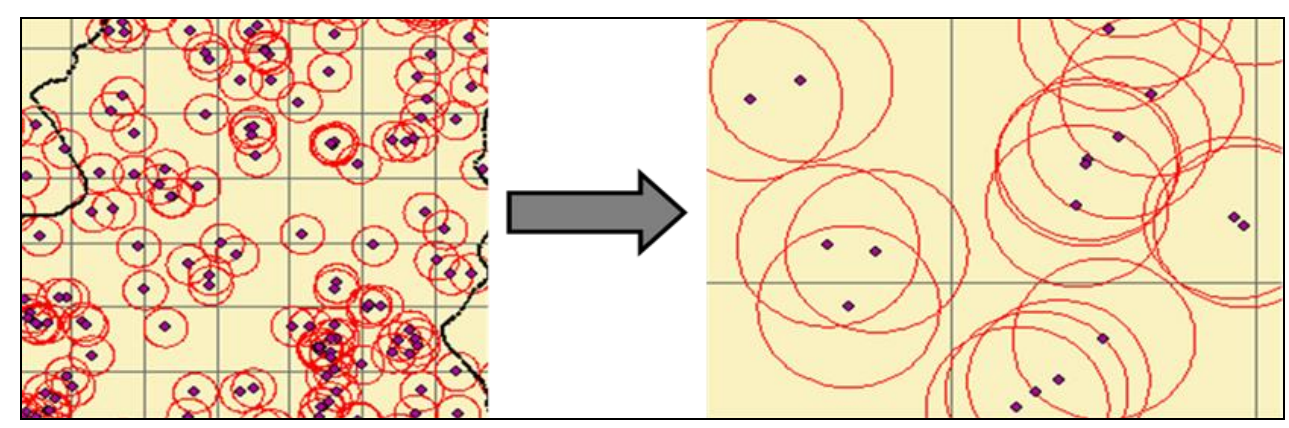

Figura 2 - Grade de 1x1km, buffers e o resultado da operação "Spatial Join"

Após esta operação, exportou-se a grade vetorial com os valores de área para cada pixel da grade de $1 \mathrm{x} 1 \mathrm{~km}$ para o formato matricial (raster). A Figura 3 mostra o resultado.
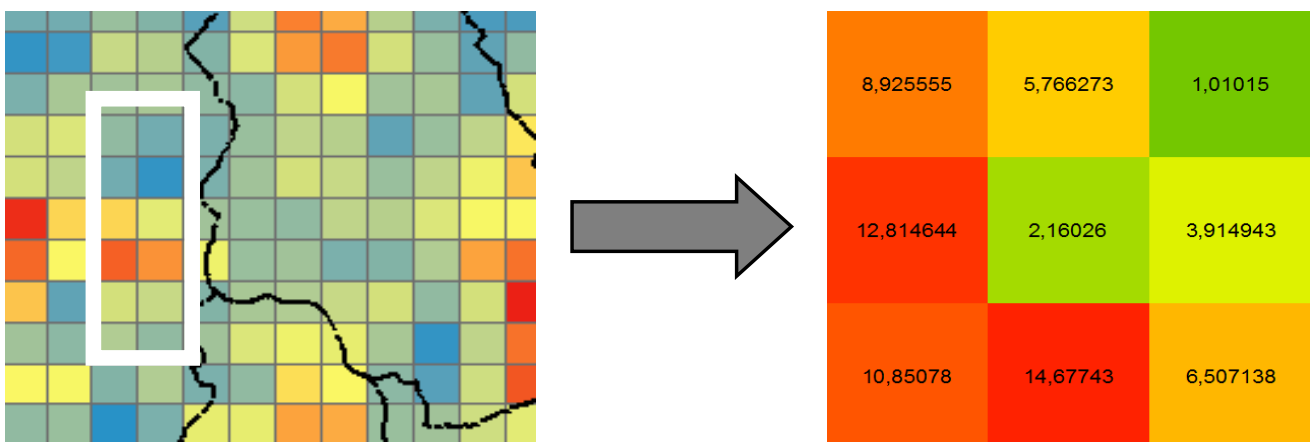

Figura 3 - Raster contendo o somatório de áreas de alagamento em cada pixel da grade de 1x1km, dividido pela área do círculo de $300 \mathrm{~m}$.

De posse do arquivo matricial necessitava-se ainda construir um arquivo com o mesmo formato contendo os dados referentes ao NEA em cada bacia, para então poder fazer a multiplicação de ambos e identificar para cada dia, levando com consideração o histórico, quais as áreas com maior probabilidade de ocorrência de um alagamento.

\section{Resultados}

A título de exemplo, foi utilizado o NEA gerado na verificação (ano de 2010) para quatro datas. A Tabela 1 mostra os dias escolhidos, o número observado de alagamentos e o NEA. 
Tabela 1 - Exemplo para 4 dias específicos do número de alagamentos observados versus NEA

\begin{tabular}{|c|c|c|c|c|c|c|c|c|c|}
\hline & \multirow{2}{*}{$\begin{array}{c}\text { Total } \\
\text { histórico }\end{array}$} & \multicolumn{2}{|c|}{$13 / 12 / 2010$} & \multicolumn{2}{|c|}{$30 / 10 / 2010$} & \multicolumn{2}{|c|}{$24 / 09 / 2010$} & \multicolumn{2}{|c|}{$23 / 04 / 2010$} \\
\hline & & Obs. & NEA & Obs. & NEA & Obs. & NEA & Obs. & NEA \\
\hline Barigui & 796 & 9 & 6 & 4 & 2 & 6 & 2 & 7 & 5 \\
\hline Belem & 642 & 6 & 3 & 2 & 1 & 1 & 1 & 0 & 2 \\
\hline Iguacu & 126 & 2 & 1 & 1 & 0 & 0 & 0 & 2 & 1 \\
\hline Atuba & 471 & 9 & 10 & 1 & 2 & 3 & 1 & 32 & 11 \\
\hline $\begin{array}{l}\text { Rib. dos } \\
\text { Padilhas }\end{array}$ & 294 & 1 & 1 & 0 & 0 & 4 & 1 & 0 & 0 \\
\hline
\end{tabular}

Elab.: Marciel Lohmann, 2011.

Como a ideia foi espacializar o NEA por $\mathrm{km}^{2}$ e identificar os locais via o histórico, dividiu-se o valor de NEA pelo número total de alagamentos em cada bacia, gerando um valor de NEA histórico (Tabela 1). Este valor foi associado ao limite de cada bacia e posteriormente este arquivo também transformado em matriz com resolução de $1 \times 1 \mathrm{~km}$. A multiplicação dos dois arquivos foi feita utilizando-se da ferramenta "raster calculator". O resultado foi outro arquivo raster contendo os valores de NEA em cada pixel de $1 \mathrm{x}$ $1 \mathrm{~km}$, ou seja, NEA por $\mathrm{km}^{2}$. Na multiplicação, os pixels da grade que fazem fronteira entre duas bacias (retângulo branco na Figura 3) conservam o valor de NEA histórico da bacia em que mais de 50\% do pixel está contido.

Tabela 2 - NEA divido pelo total histórico

\begin{tabular}{l|c|c|c|c|c}
\hline & Total & $\mathbf{1 3 / 1 2 / 2 0 1 0}$ & $\mathbf{3 0 / 1 0 / 2 0 1 0}$ & $\mathbf{2 4 / 0 9 / 2 0 1 0}$ & $\mathbf{2 3 / 0 4 / 2 0 1 0}$ \\
\cline { 3 - 6 } & histórico & NEA/Total & NEA/Total & NEA/Total & NEA/Total \\
\hline Barigui & 796 & 0,007538 & 0,002513 & 0,002513 & 0,006281 \\
\hline Belem & 642 & 0,004673 & 0,001558 & 0,001558 & 0,003115 \\
\hline Iguacu & 126 & 0,007937 & 0 & 0 & 0,007937 \\
\hline Atuba & 471 & 0,021231 & 0,004246 & 0,002123 & 0,023355 \\
\hline Rib. dos Padilhas & 294 & 0,003401 & 0 & 0,003401 & 0 \\
\hline
\end{tabular}

Elab.: Marciel Lohmann, 2011.

A partir do método proposto para espacialização do NEA, o primeiro resultado gerado foi o mapa contendo o número de alagamentos histórico registrado por $\mathrm{km}^{2}$ (Figura 4). Fazendo uma breve reflexão a cerca deste mapa pode-se dizer que ele traduz, tendo em vista o período analisado, exatamente qual foi o número de alagamentos por $\mathrm{km}^{2}$ em cada uma das bacias hidrográficas analisadas ou ainda para todo o município, uma informação nova e relevante podendo ser utilizada pelos órgãos do poder público responsáveis por estabelecer as políticas públicas no sentido de mitigar os impactos provenientes dos alagamentos, 


\section{OS DESAFIOS DA GEOGRAFIA FÍSICA NA FRONTEIRA DO CONHECIMENTO \\ Instituto de Geociências - Unicamp \\ Campinas - SP \\ 28 de Junho à 02 de Julho de 2017}

Este mapa mostra ainda quais são os locais mais e menos atingidos por alagamentos ou ainda os locais que até 2010 nunca foram atingidos. Neste sentido, fica evidente que alguns locais foram atingidos por até 40 alagamentos enquanto em outros ocorreram poucos alagamentos.

Sob outra perspectiva, esta informação torna-se de suma importância, pois revela a estimativa de quantos alagamentos são esperados de ocorrer no futuro por ano e por $\mathrm{km}^{2} \mathrm{em}$ Curitiba, bastando para isso dividir a informação contida no mapa por 6 anos (período analisado). Tal estimativa, associada à identificação dos locais mais atingidos pelos alagamentos poderá ser de grande utilidade para o planejamento e preparação para eventos extremos e até mesmo na indicação dos locais prioritários que deverão ser contemplados com medidas de cunho estrutural.

Ainda, este mapa pode estar traduzindo um cenário de vulnerabilidade a alagamentos em Curitiba, com o diferencial de que o mesmo foi construído tendo como base os dados históricos, ou seja, a gênese desse mapa não se deu através da combinação de variáveis do meio físico (solos, relevo, geologia, vegetação entre outros) e do meio socioeconômico (população, renda, escolaridade ente outras) com a atribuição de "pesos" a cada uma das classes utilizando-se de critérios muitas vezes subjetivos, mas sim a partir de dados que representam exatamente o que ocorreu no passado. A partir de uma simples normalização, por exemplo, o mesmo pode ser interpretado também como mapa das áreas mais vulneráveis a alagamentos. Com a associação da precipitação em tempo quase real, ter-se-ia a informação de risco a alagamentos em Curitiba.

As Figuras 5 a 6 mostram os mapas com o número esperado de alagamentos por $\mathrm{km}^{2}$ por dia, resultantes da multiplicação entre o primeiro resultado (apresentado na Figura 4) versus o NEA previsto dividido pelo total histórico da bacia. Os tons em azul e verde representam menor NEA por $\mathrm{km}^{2}$ e por consequência locais com menor probabilidade de ocorrer um alagamento. Os tons em amarelo, laranja e vermelho representam maior NEA por $\mathrm{km}^{2}$ e também maior probabilidade respectivamente. 
XVII Simpósio Brasileiro de Geografia Fisica Aplicada

I Congresso Nacional de Geografia Física
OS DESAFIOS DA GEOGRAFIA FÍSICA NA FRONTEIRA DO CONHECIMENTO Instituto de Geociências - Unicamp

Campinas - SP

28 de Junho à 02 de Julho de 2017

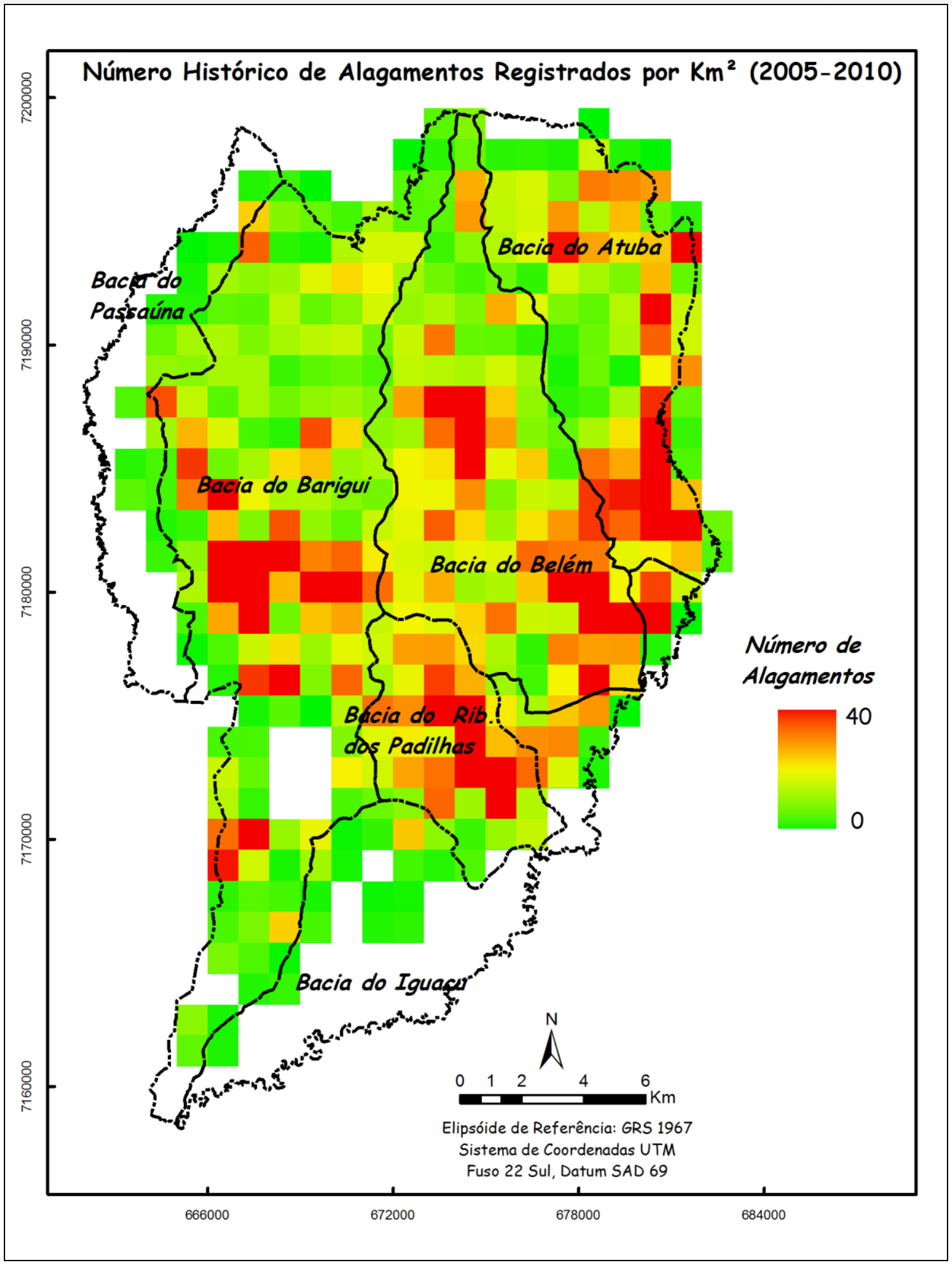

Figura 4 - Número histórico de alagamentos registrados por km² (2005-2010) 
XVII Simpósio Brasileiro de Geografia Fisica Aplicada

I Congresso Nacional de Geografia Física
OS DESAFIOS DA GEOGRAFIA FÍSICA NA FRONTEIRA DO CONHECIMENTO

Instituto de Geociências - Unicamp

Campinas - SP

28 de Junho à 02 de Julho de 2017



Figura 5 - Número esperado de alagamentos por $\mathrm{km}^{2}$ para o dia 23/04/2010. Obs: os círculos em vermelho representam os alagamentos observados nesse dia

No dia 23/04/2010 nota-se que a bacia do Atuba está mais sujeita a ocorrência dos alagamentos. Em virtude de o NEA ser previsto como zero na bacia do Ribeirão dos Padilhas, não há probabilidade de ocorrência de alagamentos. E no dia 13/12/2010, com exceção da bacia do Passaúna, todas foram atingidas, sendo a do Atuba e do Barigui com maior intensidade, com NEA de 10 e 6 respectivamente. 


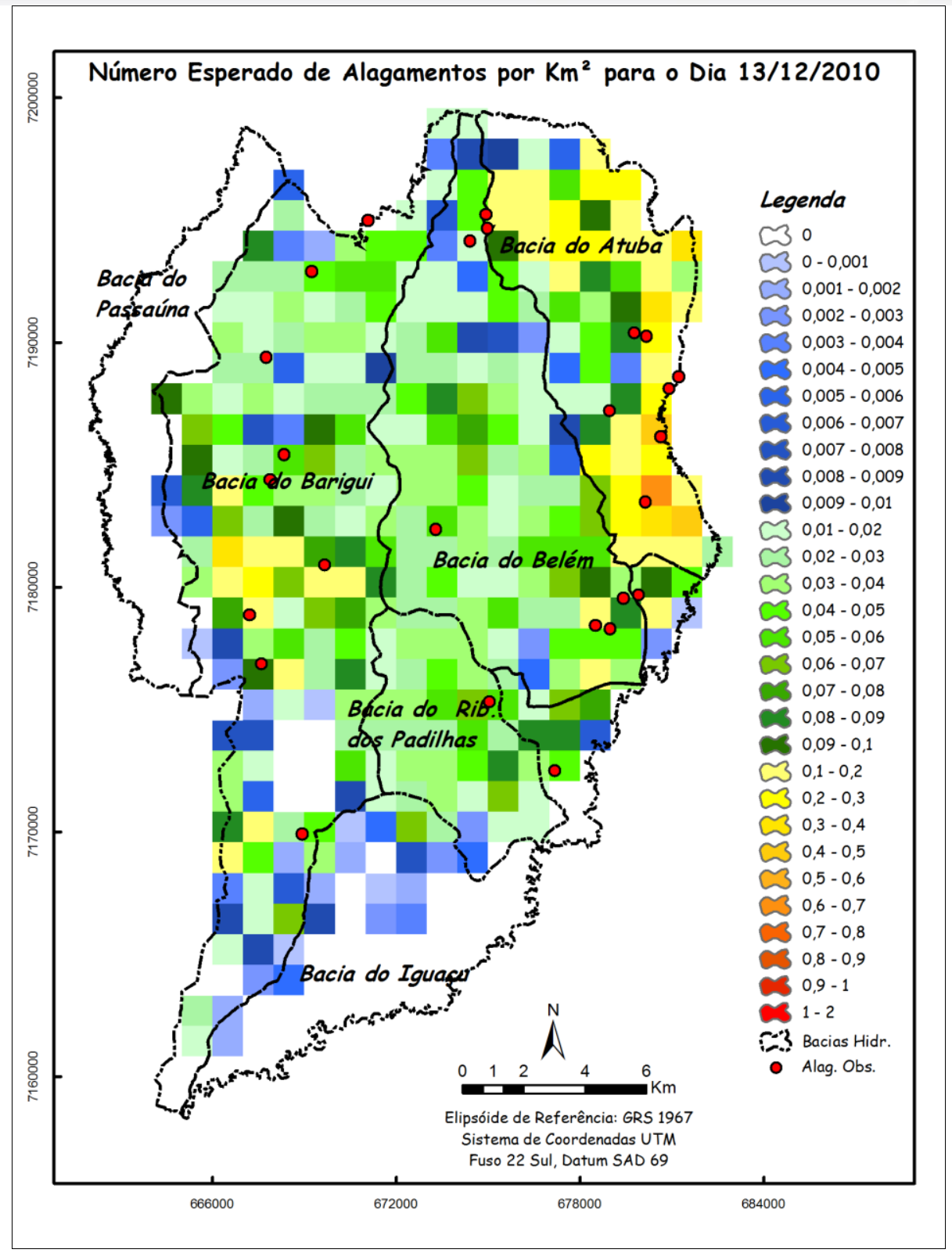

Figura 6 - Número esperado de alagamentos por $\mathrm{km}^{2}$ para o dia 13/12/2010. Obs: os círculos em vermelho representam os alagamentos observados nesse dia.

De forma geral pode-se verificar que os pontos de alagamentos observados nos respectivos dias analisados conferem bom grau de confiabilidade aos resultados apresentados nos mapas, já que os mesmos localizam-se sobre as áreas indicadas como de maior NEA por $\mathrm{km}^{2}$. 


\section{Considerações Finais}

A partir das espacializações do NEA e da probabilidade pode-se dizer que tais produtos cartográficos respondem de forma interessante para identificar as áreas em cada bacia hidrográfica com maior probabilidade de serem atingidas pelos alagamentos.

Como proposta e pensando que tais mapas poderiam ser gerados também de forma operacional e utilizados por técnicos da Defesa Civil e Bombeiros, vê-se grande vantagem na utilização de tal metodologia para espacialização do NEA, principalmente no que diz respeito a sua atualização dinâmica, ou seja, de posse das informações cartográficas (latitude e longitude) referentes aos alagamentos ocorridos durante um determinado período, seja ele um dia, uma quinzena ou ainda mensalmente, as mesmas podem ser adicionadas ao histórico, gerado novamente os buffers, a grade com as respectivas áreas de alagamento por $\mathrm{km}^{2}$ e finalmente a espacialização do NEA, com taxa de atualização frequente.

Cabe aqui, além de mostrar o potencial, também fazer uma crítica a metodologia proposta, principalmente no que tange ao tamanho do buffer. Sabe-se que a opção de definir um raio de $300 \mathrm{~m}$ ao entorno de cada ponto de alagamento pôde não ser a mais precisa. No entanto, como já comentado, em função da inexistência de tal informação fez-se essa escolha baseada no conhecimento empírico da defesa civil. Sabe-se ainda que existem iniciativas por parte de órgãos ligados ao governo municipal de mapear a área exata atingida por um alagamento com auxílio de um APP instalado em um aparelho de celular ou Tablet. Tal equipamento será levado pelos técnicos da Defesa Civil, Bombeiros, Guarda Municipal entre outros, para os locais de atendimento de ocorrências, sendo utilizados, portanto para tal tarefa. Dessa forma, a utilização dos buffers seria substituída ou então as informações mais exatas da área de abrangência de um alagamento, adicionadas as informações já existentes.

\section{Bibliografia}

GONÇALVES, F. M. Utilização de Radar Meteorológico em Hidrologia. 2005. 116 f. Dissertação (Mestrado em Engenharia) - Escola Politécnica da Universidade de São Paulo. São Paulo.

LOHMANN, M. Regressão logística e redes neurais aplicadas à previsão probabilística de alagamentos no município de Curitiba, PR. 2011. 231 f. Tese (Doutorado em Geografia) - Universidade Federal do Paraná. Curitiba.

MUNICH-RE - Topics Geo, Annual review: Natural Catastrophes 2004. 2005.

PEREIRA FILHO, A. J., Integração dos dados de Precipitação do Radar Meteorológico e da Rede Telemétrica de São Paulo via Análise Objetiva Estatística. Relatório Técnico, FCTH. 1999

PEREZ FILHO, A.; VANNUCHI, S. H.; MATTOS, L.; ORSI, L.; VICENTE, A. K.; VICENTE, L. E. Monitoramento e gerenciamento de bacias urbanas associados à inundação: diagnose da bacia do Ribeirão Quilombo na Região Metropolitana de Campinas utilizando geotecnologias. Revista do Departamento de Geografia, 19 44-54 p. 2006. 